Volume 5, Issue 2

September 2012

\title{
Telefantasy's Conflicting Verisimilitudes: Composite Genre and The X-Files
}

\author{
STEVEN GIL, University of Queensland
}

\begin{abstract}
When discussed as a genre, Telefantasy may be regarded as a hybrid category because it subsumes existing labels. Although Telefantasy is a composite genre, the characteristics of its constituent elements - namely Science Fiction, Fantasy and Horror - are often in conflict, requiring an appraisal of the tensions between them. This article explores the prospects of using Telefantasy as a generic classification by showing the collective presence of these different genres within The X-Files (1993-2002). It traces the historical interaction between the three genres that make up Telefantasy through a series of examples from Edgar Allan Poe to H.P. Lovecraft and The Twilight Zone (1959-1964), thus providing a historical grounding for generic interaction. The present article forms part of a larger project concerning the interaction of generic motifs in North American cultural history. Here, the focus of that project is directed at examining Telefantasy and the utility of composite genre to the study of television programs.
\end{abstract}

\section{KEYWORDS}

Edgar Allan Poe, Fantasy, Horror, H.P. Lovecraft, Science Fiction, Telefantasy, The X-Files.

\section{Previous Theorisations}

To begin, it is necessary to position the article in relation to existing academic discussions of Telefantasy. Sue Short (2011) provides the most recent and comprehensive account in which she defines Telefantasy as 'shows with an SF [science fiction], fantasy, or supernatural element' (Short, 2011: 1). Short's definition appears to be less an account of a new genre and more a broad category that encompasses any text with certain features that may assign them to an existing genre. This conceptualisation is reinforced by Catherine Johnson's account for the origin of Telefantasy:

[W]ithin fan circles 'telefantasy' is commonly used as a broad generic category to describe a wide range of fantasy, science-fiction and horror television programmes ... unlike genres such as science-fiction and horror, telefantasy is not a term used by the industry or by general audiences... it is rather a way of separating out those texts that 
Volume 5, Issue 2

September 2012

are of interest or could be included within a canon of sorts constructed by a specific set of viewers. (Johnson, 2005: 2)

For a 'specific set of viewers' the term operates as a kind of umbrella classification, which subsumes the existing generic labels of Science Fiction, Fantasy, and Horror. Note also that another named genre, Horror, is added to those which Short recognises (Science Fiction and Fantasy). In proceeding discussions, these three genres will form the main focus when expounding on the potential complications of Telefantasy.

One may ask why a term with such limited usage yet broad inclusivity should be imported into academic treatments of television. To such a question Johnson provides the following answer, arguing

The boundaries between fantasy, science fiction and horror have consistently problematised explorations of these genres ... Over and above this, the tendency towards generic hybridity within television has proved problematic for the study of television genre... For example, The X-Files can be categorised as a science-fiction series ... and as a detective series ... is also frequently horrific... and embedded in the action-adventure form common to series television in the US. (Ibid.: 3)

Inclusion in multiple genres is not necessarily a problem as certain aspects of the series will be highlighted depending on what genre is being discussed. For instance, a study of detective series on television may mention The X-Files (1993-2002), discussing those elements that it shares with NYPD Blue (1993-2005), Law \& Order (1990-2010), and CSI: Crime Scene Investigation (2000- ), as well as noting the elements which distinguish it from these more typical examples. However, in such a case we have acknowledgment of peculiarity due to maintaining a sense of generic boundaries instead of the reduction to similarity that appears to be present in Telefantasy. Johnson is also attaching the hybridity and combination of generic styles to a single medium. When considered historically though, there is reason to believe that this same aspect is present outside of television.

Given that Short refers to Telefantasy as a 'genre' and states that Johnson's work is arguing that Telefantasy 'constitutes a discernible genre' (Short, 2011: 4), we may expect to see the term being applied as such. When Telefantasy becomes the genre of designation, it risks displacing other potential labels such as Science Fiction, Fantasy, Horror, or detective fiction. Implicit in the label is a distinct nature that incorporates elements of any or all of these, but is nevertheless a separate entity. However, what we see is Telefantasy being used in much the same way as Johnson described its use in fan communities: to cover a wide range of texts. Deployed by Short, Telefantasy is used in precisely that manner to collectively discuss texts from arguably different genres which may otherwise not be considered together unless bound by a term of similar breadth such as "quality" or "cult." Indeed, we may cite "quality TV" and "cult TV" as similar designations as each has given rise to compendiums of academic 
work which include examples of Science Fiction, Fantasy, and Horror television together (see Gwenllian-Jones and Pearson, 2004; Jancovich and Lyons, 2003). In pointing the confluence out though, the question of why these designations are insufficient remains. The view that a new genre is specifically required would account for the use of Telefantasy as such.

Arguably, the mixture of generic features taken from Science Fiction, Fantasy, and Horror in one text may be required before regarding Telefantasy as a genre in its own right. Problems alluded to by Johnson suggest a difficulty in isolating the generic identity of texts such that a new classification is necessary if those issues are to be overcome. By focusing specifically on The X-Files this article seeks to demonstrate how Telefantasy can operate as a means to examine a single case study where features of a series give rise to problems if a mono-generic classification is sought. However, such problems do not necessarily impact upon all series designated as Telefantasy. Viewing Telefantasy as a 'discernible genre' requires the text in question to fit most appropriately into that new classification. Such hybridity is also contingent on the mutual presence of generic frameworks and it is this that gives rise to the conflict of verisimilitude which is discussed at greater length below.

Why dissolve the previous classifications of Science Fiction, Horror, and Fantasy? For Johnson, Telefantasy series are those which contain 'events and objects that confound culturally accepted notions of what is believed to be real' and therefore 'can be understood to engage with regimes of "non-verisimilitude", she elaborates by citing two typologies of verisimilitude:

Generic verisimilitude corresponds to what is accepted as plausible or likely within the expectations of a particular genre... Socio-cultural verisimilitude does not equate directly with truth or reality, but with broader culturally constructed and generally accepted notions of what is believed to be true... What is plausible within a sciencefiction film (and other non-versimilitudinous genres)... conflicts with accepted notions of 'reality.' (Johnson, 2005: 4)

The confounding Johnson alludes to results then from a disjuncture of expectations, wherein socio-cultural and generic verisimilitudes accept different possibilities. Quite problematically the contrast is not between verisimilitude and non-verisimilitude but rather within typologies which indistinctly render the texts 'non-versimilitudinous'. The rationale for that conclusion is unclear. Moreover, if socio-cultural verisimilitude is not reality then conflict with its expectations cannot be read as conflict with the real.

Johnson's discussion of these typologies is anchored in Steve Neale's work. 'Regimes of verisimilitude ['various systems and forms of plausibility, motivation and belief'] vary from genre to genre,' writes Neale. 'Bursting into song is appropriate, therefore probable therefore believable - in a musical, but not in a war film or a thriller' (Neale, 2000: 32). Compilation genres such as Telefantasy could therefore be seen to enable a broader scope for narrative events by the inclusion of multiple generic verisimilitudes. A simple example in line 
with Neale's description would be the episode 'Once More, with Feeling' (6.07) from Buffy the Vampire Slayer (1997-2003), a series regarded as Telefantasy by both Johnson and Short. The episode maintains the usual focus of the series on the eponymous vampire slayer and her friends as they battle demonic forces in the fictional town of Sunnydale but adds the ability for characters to burst into song by also being a musical. That capacity is normalised into the series by being framed as the result of a demon's magical influence on the characters. Such a situation indicates that the variation between genres is not automatically sufficient to entail each possessing its own impermeable regime of verisimilitude.

Even though genres can be combined, Neale's observation still provides a sense that genre confines what is plausible and believable within a text. Restriction affords a way to read genre (Turner, 1999: 44-5) whereby focus is placed on the constraints entailed by generic verisimilitude. Regarding the other sort of verisimilitude that Johnson mentions, one may also say that socio-cultural beliefs factor into the assessment of a text. For this, Neale's own account draws heavily upon the work of Tzvetan Todorov who contrasts what is deemed believable within a given genre - its rules of the verisimilar - with 'what readers believe to be true' (Todorov, 1981: 118-9). Such a view allows fiction the scope to present what is not considered real, while outside of fiction different standards are involved. What the division of generic and socio-cultural verisimilitudes does is to provide recognition that standards of plausibility exist outside of a genre or text. Describing these external standards as 'sociocultural' however is assuming that such verisimilitude is judged by socially and culturally contingent factors. That same assumption is neither made nor implied by the present article. Debating the status of the means through which "truth" and "reality" are established outside of a generic basis is a major digression from topic. What concerns us here is that a distinction is being made between what is acceptable within the texts, and outside of them. Subsequent discussion throughout the article retains the distinction of internal and external verisimilitude.

\section{Generic Combination and Conflict}

The $X$-Files is consistently described as arising from an amalgam of influences, suggesting it may lend itself particularly well to an assessment of the need for a composite genre. David Lavery contends that series creator Chris Carter 'fashioned The X-Files out of conventions and formulae originating in police procedural, suspense, action, science-fiction and horror genres' (Lavery, 2004: 242). Listing 'traditional horror' including Frankenstein (1931), '1950s B sci-fi,' '1970s television' including 'Carter's stated inspiration' - Kolchak: The Night Stalker (1974-1975), 'conspiracy thrillers', 'early 1990s blockbusters,' and Twin Peaks (1990-1991) as source material for the series, Karen Backstein argues that 'week after week, The X-Files simply switched genres and the styles associated with them, from pure science fiction and chilling horror to whacky postmodern comedy and romantic drama' (Backstein, 2004: 117). Certainly then, this is a series which combines multiple generic motifs. What is also important to note is that it is possible for an episode to possess a generic identity without 
that impacting the series as a whole. Such a notion will be revisited later in the article. What also requires attention is that whilst both Lavery and Backstein's accounts of The X-Files' origins refer to Science Fiction and Horror, neither mentions Fantasy. Johnson's similar appraisal of The X-Files' multi-generic status contains the same omission. This is significant for two reasons: firstly, because Science Fiction, Horror, and Fantasy are regarded as the three main constituents of the body of texts called Telefantasy; and secondly, because Fantasy alone appears in the very name of the category.

Closer attention to the separate genres of Fantasy, Science Fiction, and Horror is now required to further a generic understanding of Telefantasy. Providing a summary of the use of the term Fantasy, Rosemary Jackson writes:

As a critical term, 'fantasy' has been applied rather indiscriminately to any literature which does not give priority to realistic representation: myths, legends, folk and fairy tales, utopian allegories, dream visions, surrealist texts, science fiction, horror stories... A characteristic most frequently associated with literary fantasy has been its obdurate refusal of prevailing definitions of the 'real' or 'possible', a refusal at times amounting to violent opposition. (Jackson, 1981: 13-4)

Both in broadness and in its incorporation of various labels, there is confluence between what Jackson identifies as the previous critical deployment of Fantasy and Johnson's theorisation of Telefantasy. However, we cannot actually say that Science Fiction and Horror are being read as sub-categories as indicated by Jackson's account and must, therefore, assume that Fantasy maintains an independent status. Both Johnson and Short have already been seen to explicitly mention Fantasy alongside Horror and Science Fiction. What does persist is the conceptualisation of the category as encompassing all genres which are regarded as divergent from "prevailing definitions of the "real" or "possible." Reinforcing the sense of conflict, William R. Allen observes: 'a fantasy is a story based on and controlled by an overt violation of what is generally accepted as possibility; it is the narrative result of transforming the condition contrary to fact into "fact" itself' (Allen, 1976: x). Jan Delasara raises serious questions for seeing that element of departure as cause to consolidate multiple labels by rightly contending:

Fantasy, science fiction, gothic literature, supernatural fiction, dark fantasy, horror, and magical realism - all of these literary types feature content that deviates from common-sense ideas about reality and so-called normality. While each type can be referred to as a "genre," they are difficult to package together into a neatly interrelated and integrated grouping. Horror and science fiction are not branches of a tree called fantasy, and the only defining characteristic of horror as a genre seems to be the horror itself.' (Delasara, 2000: 62) 
Contained therein is a similar recognition of an external verisimilitude that each genre moves away from. Having content which challenges - or fails to meet - external standards, however, is seen as insufficient to warrant assimilation into a common category. Such features are too loose to justify outright combination. Resultantly, we return to the problematic issue of Telefantasy's broadness of scope, which breaks down in more nuanced appraisals.

Treating Fantasy, Science Fiction, and Horror as individual generic classifications, one can ask whether these are capable of being combined. Following Delasara we may view Horror as a genre of affect (Delasara, 2000: 65), with the feeling being equally capable of arousal by "realistic," Science Fictional, or Fantastical narratives. As with the Musical, Horror could be seen as capable of being layered on top of other genres without causing conflict. Conciliation is not as readily available for Fantasy and Science Fiction which are frequently held in opposition. Bruce H. Franklin regards the avoidance of the supernatural as the key difference between Science Fiction and Fantasy (Franklin, 1966: 94). Deviations from the 'real' are effected by non-magical means, as Kingsley Amis indicates when describing Science Fiction as departing from reality on the basis of 'a situation that could not arise in the world we know, but which is hypothesized on the basis of some innovation in science or technology, or pseudo-science or pseudo-technology' (Amis, 1960: 18). Pointing to the implication of the genre's title, Gregg Rickman asserts that Science Fiction 'is quite commonsensically fiction about science, and the changes new technologies might bring about' (Rickman, 2004: xiv). Completing the contrast, famous Science Fiction author Isaac Asimov observes of Fantasy that it portrays surreal backgrounds that cannot reasonably be supposed to be derived from our own [world] by any change in the level of science and technology' (Asimov, 1981: 18). Neither Science Fiction nor Fantasy fully replicate an external verisimilitude but stay distinct because each produces its deviation through different means.

Why, then, if there is cause to distinguish Science Fiction from Fantasy, are the two nevertheless combined? Short provides some insight when elaborating on the inclusion of events and objects contrary to external beliefs, stating:

Telefantasy hinges upon the suspension of disbelief, asking viewers to withhold their skepticism and take certain plot points as read ... For the following analysis the term is used to describe series that contain fantastical elements, whether it be specific figures (such as shapeshifters, vampires, or people with superhuman abilities), phenomena (i.e. portals to other dimensions), or technologies not yet known to exist (including machines capable of extensive space travel or time-travel). Whether or not they are supernatural or science fictional in origin, Telefantasy encompasses both. (Short, 2011: 10)

Again, Telefantasy seems to be a category for placing anything that may otherwise be called Science Fiction or Fantasy (or Horror, or several more existing genre labels). Although a difference between the supernatural and the scientific is acknowledged, it is not regarded by Short as cause to separate texts - all 'fantastical elements' are effectively read as equal. Of 
additional interest in Short's elucidation is her use of the phrase 'suspension of disbelief.' This is a problematic phrase if one aims to equate Science Fiction with Fantasy. According to Sam Moscovitz, Science Fiction is "identifiable by the fact that it eases the "willing suspension of disbelief" on the part of its readers by utilizing an atmosphere of scientific credibility for its imaginative speculations' (quoted in Delasara, 2000: 62). Vivian Sobchack writes that Science Fiction films 'strive primarily for our belief, not our suspension of disbelief', contending 'this is what distinguishes them from fantasy films' (Sobchack, 1987: 88). Also identifying the means through which the attempt at believability is effected, James Gunn takes this a step further by describing the content of Science Fiction as 'presented plausibly and which the reader is supposed to accept as real for scientific reasons, not as a willing suspension of disbelief' (Gunn, 2005: 85). Science Fiction is therefore reaching outside of a sense of generic verisimilitude to achieve plausibility - narratives are not regarded as plausible because they are read as Science Fiction but because they use science.

Connection to external justification significantly undermines the equation of Science Fiction and Fantasy. This demonstrates that Science Fiction is using more than socio-cultural expectations as a way to achieve verisimilitude. Gregory Benford challenges the perception that plausibility is defined relative to either socio-cultural or merely genre-based factors in observing of the inclusion of science:

Using science in fiction introduces tools not generally available to ordinary fiction. The most relevant of these is constraint - defining what is possible or plausible... This rigor creates a fundamental tension between dramatic needs and the demands of accuracy and honesty.' (Benford, 1986: 83)

Accuracy and honesty indicate the fact that this plausibility resides outside of the world of fiction writing where actual science, acting as an intellectual resource, limits what can be done. Clarifying the combination of reality and difference that marks the genre, Carl D. Malmgren demonstrates that while Science Fiction does not try to re-present reality, its deviations - fictional inventions, ideas and speculations - are an addition or extension of what we experience in actuality, operating within the confines of scientific discourse (Malmgren, 1991: 8-9). Such an argument could be used to distinguish Science Fiction and, more specifically, Science Fiction television (SFTV) from Telefantasy.

However, it is Telefantasy with which this article is concerned. In pursuing a single series in which Science Fiction, Fantasy, and Horror are seemingly all present, this article does not encounter the need to justify the inclusion of two distinct categories under a single title. An example of Telefantasy should preferably encompass all in the one space. Otherwise we may well regard it as better understood in terms of Fantasy or Science Fiction alone. The importance of Telefantasy as a genre is seen here to rest in addressing television programs which use scientific and supernatural motifs as well as having the capacity to horrify, making them a genuine, multi-generic text. Therefore the utility of Telefantasy rests in it doing what 
Volume 5, Issue 2

September 2012

established generic classifications do not. The X-Files is argued to be a potential one example which has the capacity to resist clear generic classification.

\section{Only 'tele'-fantasy?}

Hybrid genres are not unique to television. In regarding the generic and historical context of The X-Files as connected to works by Edgar Allan Poe and H.P. Lovecraft, this article is also concerned with print media. That focus may be regarded as valid because the work of these two authors specifically combines Science Fiction, Fantasy, and Horror, therefore acting as a historical antecedent to Telefantasy and providing additional insight concerning the interaction of its three named constituents. A way of consolidating literature and television into a single discussion is to focus on aspects common to each. David Bianculli claims that the likeness of television to literature is 'obvious' when looking at 'the content instead of the delivery system' (Bianculli, 2000: 138). Placing further attention on content and also alluding to the reasons for audience interest, James Broderick asserts that 'Star Trek is literature' by arguing:

Trekkers and casual observers continue to be drawn to Star Trek for the same reason one seeks the satisfaction of literature - to discover the depth and complexity of our own world, to help find one's place in the universe ... the reader's expectations are the same: a tale which can be enjoyed for its plot and characters, or as a deeper meditation on the human condition.' (Broderick, 2006: 5-6)

What such assessments can serve to establish is the historical interaction and continuity of cultural motifs, despite the difference in their mode of dissemination. We can see the programs as separate from the technology and artifice of television. In no way does this discount the importance of the context of production which still remains an important consideration in the analysis of individual examples. Indeed, Jan Johnson-Smith notes the 'use of the segment ... six acts, including the trailer and tag' in The X-Files where 'the episodic narrative rises intermittently to strong suspense to permit the commercial interruptions of American television' (Johnson-Smith, 2005: 72). As such, television as medium is written into the structure of each episode. Nevertheless, marked differences have been noted in the removal of television programs from their original means of transmission. Through the transfer to DVD, 'texts are converted from being primarily moments in a schedule... to symbolically bounded objects more akin to artworks or novels, which audiences can search for or keep as digital files, or purchase as DVDs/legal downloads' (Hills, 2007: 45). Situating new media as the mechanism by which television has become increasingly literary, Matt Hills argues 'the reproducibility of TV (and the near-perfect freezing of its frames) ... makes its texts more akin to those of written rather than oral culture' (Ibid.: 48). Further justification of the mutual consideration of print (literature) and audio-visual (television) media comes through attention to genre. 
Volume 5, Issue 2

September 2012

This article is primarily focused on the question of genre, and genre is a specific element that can transect media. That is the case with Science Fiction which 'has established itself across a variety of media' (Cornea, 2007: 5). A similar claim can be made of Horror which is a genre present in literature (such as the works of Stephen King), and film (the Nightmare on Elm Street series (1984-2003, 2010). Similarly, Fantasy has a long and prolific literary presence (a notable example being J.R.R. Tolkien's The Lord of the Rings trilogy (1954-1955). That Science Fiction, Fantasy, and Horror are all capable of appearing on television is indicated by the inclusion of all three in theorisations of Telefantasy. Historical discussion of Telefantasy as genre would therefore be able to include texts from at least film and literature despite the 'tele' of the title seemingly restricting it to one medium. To discount similar texts purely on the grounds of medium specificity is to potentially ignore the influence and importance of earlier works that also mix Science Fiction, Fantasy and Horror. A level of inclusivity is not necessarily a drawback, as Neale argues:

$[\mathrm{C}]$ onventional definitions of genre are often narrow and restrictive ... traditional accounts of a number genres are inaccurate or incomplete ... aesthetic and cultural theories are prone to overgeneralization ... my own view is that many of these accounts have been driven by critical and theoretical agendas rather than by commitment to detached empirical analysis and thorough industrial and historical research. (Neale, 2000: 1)

Industrial components are outside of the scope of this article, but the impetus to not be too restrictive when considering the history of a genre remains. Todorov provides a notable distinction in establishing a contrast between historical genres and theoretical genres - 'the first would result from an observation of literary reality; the second from a deduction of a theoretical order' (Todorov, 1973: 13-4). Theory and history, however, may not be clinically separated, and as Gary Westfahl points out, 'criticism functions as the necessary binding force that creates, sustains, and preserves the integrity and identity of the genre' (Westfahl, 1998: 3). In other words, discussions of a genre feed into how the genre is identified and can, as Neale suggests, guide accounts. Here we are examining texts which combine Science Fiction, Fantasy and Horror and are thus not guided by theoretical expectations, besides the intention to test whether such examples are present.

If we accept that The X-Files exhibits characteristics of multiple genres, it is reasonable to assume that such a combination is a historically valid view. In testing the generic history of the series, Jason P. Vest argues 'The X-Files, for all its originality and the articulate manner by which it captures the uneasy attitude of American viewers toward the collusion of high technology and governmental power, is part of a lineage that stretches back to the earliest days of science fiction' (Vest, 2007: 107). Although Vest is only concerned with a connection to Science Fiction, a look at that genre's 'earliest days' reveals a notable degree of generic 
permutation. For example, Mary Shelley's Frankenstein (1818) provides the starting point for Brian Aldiss' history of Science Fiction, Billion Year Spree (1973); however, as Eric Rabkin and Robert Scholes remind us, "when Mary Shelley wrote Frankenstein, science fiction had neither a name nor any recognition as a separate form of literature' (Rabkin and Scholes, 1977: 7). Similarities to the tale of the Golem from Jewish folklore have been used to align the novel with more fantastical narratives instead of Science Fiction (Del Ray, 1980: 15). Additionally, film adaptations provide a connection to Horror as do Shelley's own words from her introduction to the 1831 edition where the author speaks of wanting to write a tale 'which would speak to the mysterious fears of our nature, and awaken thrilling horror - one to make the reader dread to look round, to curdle the blood, and quicken the beating of the heart' (Shelley, 1990 [1831]: 169). Frankenstein acts as an explicit reference point for one episode of The X-Files (5.05, 'The Post-modern Prometheus') as well as a thematic one for others including 'Colony' (2.16) and 'End Game' (2.17), both of which are significant to the series' conspiracy meta-narrative (Vest, 2007: 108-13). The interaction and ambiguity of Science Fiction, Horror, and Fantasy thus has historical roots.

Further evidence of such a historical lineage can be found in the work of Edgar Allan Poe (1808-1848). Although his name is rarely mentioned in public discussions of Science Fiction and he may be more frequently cited as a progenitor of Horror, Poe's was one of the first names to be connected to Science Fiction. When Amazing Stories editor, Hugo Gernsback coined the term 'scientifiction' (later to be become Science Fiction), he described it as 'the Jules Verne, H.G. Wells and Edgar Allen Poe type of story - a charming romance intermingled with scientific fact and prophetic vision' (quoted in Rabkin, 2009: 17). Poe has even been called the 'father' of Science Fiction (Franklin, 1966: 93). David Ketterer writes that, of the triumvirate cited by Gersnaback, only Verne and Wells are commonly regarded as Science Fiction writers, whilst Poe is regarded as a Horror writer (Ketterer 1974: 50). With 'The Murders in the Rue Morgue' (1841), Poe also introduced what would become detective fiction (Parrinder, 1979: 153). It has already been noted that The X-Files possesses traits of that genre as well as Science Fiction, Horror, and potentially Fantasy, with the vast majority of its narratives featuring FBI agents conducting investigations into mysterious and macarbre phenomena. We therefore have a clear precursor. Poe may be regarded as a figure working within what are now several genres, illustrating that a single author's collected works can be multi-generic. Although this connection is with a body of work and, hence, a collection of separate texts, one can regard this as cause to discuss The X-Files as a similar collection of texts, many of which may draw upon multiple (possibly conflicting) genres. More on that relation will be said in the following section.

In addition to being a reference point and significant figure for multiple genres, Poe also demonstrates an awareness that fantastical events and objects can be presented with a sense of verisimilitude that makes them convincing outside of the context of fiction. During the early nineteenth century, authors often 'conspired to pretend that they were not novelists, or that the novel was not a novel but a true story' - "true" stories having more appeal than 
fabrications (Donald Sassoon, 2006: 117). Poe himself engaged in such acts. Take for example his "Balloon Hoax" which appeared in 1844 in the New York Sun. His description of the methods used and the level of attention to detail present in the narrative was intended to "make plausible the seemingly impossible" and suggest to audiences the factuality of the work so they read the fiction as reality (Peeples, 1998: 117-8). In contrast to the obviously fictional Gulliver's Travels (Swift, 1726), Poe's 'Balloon Hoax' was realistic enough as a travelogue to fool many readers (Alkon, 1987: 250).

A similar tale suggests Poe's close association with the third part of Telefantasy's third named genre - Fantasy. 'The Unparalleled Adventure of One Hans Pfaal' (1835) involves a trip to the moon by means of balloon, a method thought questionable even by Poe himself (Del Rey, 1980: 16). Despite this partial qualm, Poe compared his work to previous fictional lunar voyages (specifically Francis Godwin's The Man in the Moone (1638), and A Voyage to the Moon (1825) by George Tucker), commenting on their essentially satirical nature and distinct lack of regard for scientific elements and stating:

In "Hans Pfaal" the design is original, inasmuch as regards an attempt at verisimilitude, in the application of scientific principles (so far as the whimsical nature of the subject would permit). (Quoted in Pierce, 1986: 26)

Not only are we provided with a historical substantiation of theoretical views of Science Fiction as using scientific elements to produce plausibility, but we also see the transference of Fantasy content into a different form of verisimilitude. It is a clear illustration of scientific verisimilitude as a concern in fiction writing. Pfaal's journey is composed with extreme attention to the amount of monitoring and diligence that goes into the operation of his craft and when describing the moon, Poe sticks closely to the astronomical conclusions of his time (Hillegas, 1979: 15). Clarifying Poe's aim in this combination of scientific detail with narrative was a note that he added to the text stating 'the application of scientific principles' increased 'the plausibility of the details of the voyage itself' (quoted in Evans, 2009: 16). In cynical comment, Marjorie Hope Nicholson writes, 'From this time on, writers of moon voyages... seek to make their planetary flights plausible... [and] pride themselves on the application of scientific principles, weighing down their imaginations and ours with technological impedimenta' (Nicholson, 1960: 239-40). Often, Fantasy may contribute only objects and events to a text regarded as an example of Telefantasy. In other words, the objects and events may be fantastical but they are rendered in accordance to a scientific verisimilitude instead of a purely generic one as shown by these examples from Poe. With that verisimilitude, these stories elude being labelled Fantasy. A similar argument can be made regarding SFTV. What of Poe's other work? Despite the presence of 'science-fictional elements' in 'Mellonta Tauta' (1849), 'The Thousand and Second Tale of Scheherazade' (1850), and 'Some Words with a Mummy' (1845), 'the essentially unreal context in which they appear militates against designating those tales primarily as science fiction' according to 
David Ketterer (1974: 73-4). One is left with the option of considering the narratives as a combination of genres in the same way it is argued here that The X-Files does not comfortably fit within a single existing category.

Similar characteristics feature in the work of H.P. Lovecraft, upon whom Poe was a significant influence (Burleson, 1983: 214). Some of Lovecraft's stories, such as 'He' (1925), directly combine his own experiences and travelogues with magic and imagination (S. T. Joshi, 2002: 388-9). Others incorporate acknowledgements of the disbelief with which the audience may approach the narrative, with arguments that the tale is a factual record of sorts. Although never presented as actual fact in the same manner as Poe's hoaxes, several narratives take the form of written accounts by eye witnesses, including the famous 'Herbert West - Reanimator' (1921-22) and 'The Call of Cthulhu' (1926). As such, Lovecraft's significance rests in the fact that he was not presenting or construing the narratives as fact outside of themselves, but still containing within them arguments for the feasibility of what his characters experience. These arguments are predicated less on overt scientific grounds and rather based on an otherwise rational character becoming convinced of events and objects outside of human understanding through direct encounters. Regarding Lovecraft's fiction, Joshi notes that it was 'critical for Lovecraft's narrators to be, on the whole, intelligent and rational' because 'if these people can be convinced that something bizarre has happened, then how can the reader refrain from being convinced?' (Joshi, 2004: 88). In The X-Files, Agent Dana Scully plays a similar role of rational mediation, functioning as a measure of how convincing the evidence is that something confounding explanation has occurred. What we are left with is a textual mediation that acknowledges the departure from external verisimilitude yet seeks to reconcile narrative events with that verisimilitude.

\section{Combined Genres on Television}

Following on from the discussion of historical antecedents which comprise mainly collected bodies of work one can examine that how genre in television can be viewed in the same way. An example which illustrates this point by readily mixing Science Fiction, Fantasy, and Horror, is The Twilight Zone. As a television series using the anthology format, The Twilight Zone is comprised of self-contained narratives that extend only as far as the segment they comprise of a given episode. The relevance of this format to Telefantasy is that multiple genres can be used over the course of the series with one narrative depicting a standard Science Fiction scenario, such as an alien incursion (1.22, 'The Monsters are Due on Maple Street'), and another overtly fantastical (3.08, 'It's a Good Life'). Therefore we meet the expectation that all genres be covered within one case study, but are still outside of the genres inhabiting the same textual space because the episodes of this anthology series are standalone narratives. However, the series does not lack coherence. As Johnson-Smith notes, 'continuity in The Twilight Zone comes not only from the opening sequence, but also from Rod Serling's introductory narration during the title sequence' (Johnson-Smith, 2005: 53). 
Furthermore, Serling's introductory narration strengthened the separation between the text and the "real world." Jeffrey Sconce comments: The Twilight Zone 'used its title and credit sequence to partition off an avowedly occult space within television itself' (Sconce, 2000: 133). Stan Beeler regards Serling as 'one of the first of the developer/writer/producer/auteur figures who are so important to the history of cult television' (Beeler, 2010: 55). Therefore, the series has a coherent identity, just as the collected works of Poe or Lovecraft do, through connection to a single figure. As an anthology series, however, The Twilight Zone is also able to explore and utilise multiple genres in relative isolation.

To approach what this article would consider a legitimate example of Telefantasy-as-genre the combination need to be direct. Thematically similar to The Twilight Zone, Kolchak: The Night Stalker differs in that it merges episodic narratives into a shared diegesis. In each episode, protagonist Karl Kolchak (Darren McGavin) seeks to uncover and substantiate the seemingly fantastic elements that lie behind local events. In a very loose way the series may be considered an anthology due to the minimal recurring cast and the fact that each episode is largely standalone: one episode features a robot (1.12, 'Mr. R.I.N.G'), another has an alien (1.03, 'They Have Been, They Are, They Will Be'), whilst others centre upon the mystical dealings of a witch (1.14, 'The Trevi Collection'), and use of Satanic magic (1.07, 'The Devil's Platform'). As with The Twilight Zone, we may regard individual episodes as exemplars of a particular genre while the series as a whole eludes singular classification. Due to its small recurring cast, Kolchak is a transitional series in the history of Telefantasy that begins to combine Science Fiction, Fantasy, and Horror into a fully integrated series. As previously mentioned, the series was a major inspiration behind The X-Files (Short, 2011: 216). The connection between the two series is even referenced within the latter when McGavin appears as Arthur Dales, the original FBI agent who investigated X-Files (5.15, 'Travelers', 6.13 'Agua Mala'). The X-Files can be seen as a partial extension of Kolchak's basic premise of weekly encounters with figures drawn from Science Fiction, Fantasy, and/or Horror. For all their similarities, Kolchak lacks the continual and recurrent narrative force and seriality of The X-Files. According to Short, The X-Files 'pioneered a format that rewarded regular viewing, via a developing mythology, while self-contained episodes encouraged casual viewers' (Short, 2011: 63). Regarding the narrative complexity of post-1980s television, Johnson-Smith writes:

Twin Peaks and The X-Files... introduced us to more sustained alternate worlds... [and] experimented with a new kind of narrative, one demonstrating complex longterm threads, some of which may lie dormant over a period but which can be drawn together at various points within the series/seasons. (Johnson-Smith, 2005: 67)

Indeed, episodes are often so connected that events may fail to make sense unless the preceding narrative is known to the viewer. Within such programs 'each minor event... is contextualised with hours of prior narrative or "backstory" that invests each moment, and the 
Volume 5, Issue 2

September 2012

characters' responses within it, with a weight of nuance and significance' (Jancovich and Lyons, 2003: 1).

One may then ask if that greater degree of narrative interconnection translates into generic unity. What we find though is that, like The Twilight Zone and Kolchak, the series appears to slip between genres. Some episodes feature Science Fictional elements with artificial intelligences (1.06, 'Ghost in the Machine'), extra-terrestrials (5.13, 'Patient X'), and genetic mutations (2.02, 'The Host'), while others seem to tend towards Fantasy, with ghosts (6.06, 'How the Ghosts Stole Christmas'), a genie (7.21, 'Je Souhaite'), and vampires (5.12, 'Bad Blood'). In Johnson's account:

the series combines stories of detection and investigation with the iconography and narratives of the science-fiction and horror genres, as Mulder and Scully explore reports of alien abductions, poltergeists, artificial intelligence, human mutations and demonic creatures, as well as being embroiled in a government plot to conceal the existence of paranormal phenomena from the general public.' (Johnson, 2005: 99)

What appears to bring the divergent elements into unity is the overarching detective story. Although Johnson is again not mentioning Fantasy, we may regard some of the events and figures she lists - namely poltergeists and demonic creatures - as indicative of that generic labelling. Inclusion of such figures alone is not necessarily enough to deny the classification of Science Fiction. As Science Fiction magazine editor and writer, John Campbell contended, 'ghosts can enter science fiction, if they're logically explained, but not if they are simply the ghosts of fantasy' (quoted in Gunn, 1986: 74). In the case of the aforementioned ghosts, genie, and vampires no logical explanation is provided. Other examples that have been dubbed Telefantasy, including the Star Trek and Stargate franchises, do include logical and scientific efforts at explanation such that one may regard SFTV as distinct to Telefantasy because these series do not raise the same genre-related issues identified in The X-Files.

By suggesting that The X-Files is difficult to label, one must demonstrate that it is neither Science Fiction nor Fantasy alone. Using the same quote from Campbell in an assessment of whether Lost (2004-2012) can be regarded as Science Fiction, David Lavery poses questions as to whether the spectral visions in the series 'meet Campbell's litmus test' (Lavery, 2008: 287-9). Delasara reminds us that 'Carter denies his show is a science fiction text' (Delasara, 2000: 63). However, Carter's own words about The X-Files being 'more in the realm of the extremely possible' (quoted in Vest, 2007: p.126), do not suggest as ready a status as Fantasy. Elucidating on the differentiation of Fantasy and Science Fiction on grounds of possibility, John Griffiths comments that when reading Fantasy we are 'aware that it is a tale of the impossible rather than of the, however remotely, possible... [and] conscious of being involved in a symbolic exercise rather than in a reflection, albeit distorted, of reality' (Griffiths, 1980: 18). Unless Carter is indicating the impossible, one may still attempt to reconcile his views to theorisations of Science Fiction. Such an attempt may conflict with 
Volume 5, Issue 2

September 2012

Darko Suvin's definition which has 'dominated... criticism since its first publication in essay form in 1972' of Science Fiction as cognitive estrangement - 'the reader enters an imaginative world different (estranged) in greater or lesser degree from the empirical world around the writer or reader, but different in a way that obeys rational causation or scientific law (it is estranged cognitively)' (Luckhurst, 2004: 7). Similar to Campbell's view, there is a requirement to adhere to a verisimilitude that makes the objects within the text logically justified. Logical grounding is not given to everything that appears in The X-Files. Providing a notable insight, Delasara indicates 'opening The X-Files' fictional universe to the concept of "extreme possibility" allowed for inclusion of the symbolically and mythically powerful motifs of traditional Horror fiction and a range of fringe experiences that included the psychic, the occult and the paranormal' (Delasara, 2000: 8). Therefore, The X-Files could be seen to work outside of a single genre.

\section{Conclusion}

The X-Files provides a case for the need to think in terms of composite genre. By examining the co-existence of genres, we see aspects that are in conflict through multiple inclusions that do not subsume all of what is depicted. Returning to an earlier question regarding why a classification outside of genre such as "quality" or "cult" could not equally suffice we may see these as insufficiently textual. Cult pertains far more to reception than content, and while quality does address particular features of the texts it does not do so in the same way as genre.

\section{References}

Alkon, P.K. (1987) Origins of Futuristic Fiction. Athens; London: University of Georgia Press.

Amis, K. (1961) New Maps of Hell: A Survey of Science Fiction. London: Gollancz.

Asimov, I. (1981) Asimov on Science Fiction. Garden City: Double Day.

Backstein, K. (2004) 'Flexing those Anthropological Muscles: X-Files, Cult TV, and the Representation of Race and Ethnicity' in Gwenllian-Jones, S. and Pearson, R.E. (Eds.) Cult Television. Minneapolis: University of Minnesota Press, pp.115-45.

Beeler, S. (2010) 'The Twilight Zone (CBS, 1959-1964)' in Abbott, S. (Ed.) The Cult TV Book, London: I.B. Taurus, pp.55-8.

Benford, G. (1986) 'Is there a Technological Fix for the Human Condition' in Slusser, G.E. and Rabkin, R.S. (Eds.) Hard Science Fiction, Carbondale: Southern Illonois University Press, pp.82-98. 
Volume 5, Issue 2

September 2012

Bianculli, D. (2000) Teleliteracy: Taking Television Seriously. New York: Continuum Publishing.

Broderick, J.F. (2006) The Literary Galaxy of Star Trek: An Analysis of References and Themes in the Television Series and Films. McFarland: Jefferson.

Cornea, C. (2007) Science Fiction Cinema: Between Fantasy and Reality. Edinburgh: Edinburgh University Press.

Delasara, J. (2000) PopLit, PopCult and The X-Files: A Critical Exploration. Jefferson: McFarland.

Del Rey, L. (1980) The World of Science Fiction, 1926-1976: The History of a Subculture. New York: Garland.

Evans, A.B. (2009) 'Nineteenth-century SF' in Bould, M., Butler, A.M., Roberts, A. and Vint, S. (Eds) The Routledge Companion to Science Fiction, Routledge, London, pp.13-22.

Franklin, H.B. (1966) Future Perfect: American Science Fiction of the Nineteenth Century. New York: Oxford University Press.

Garcia, F. and Phillips, M. (2009) Science Fiction Television Series, 1990-2004: Histories, Casts and Credits for 58 Shows. Jefferson: McFarland.

Griffiths, J. (1980) Three Tomorrows: American, British, and Soviet Science Fiction. London: MacMillan.

Gunn, J. (1986) 'The Readers of Hard Science Fiction' in Slusser, G. and Rabkin E.S. (Eds) Hard Science Fiction. Carbondale: Southern Illinois University Press, pp.70-81.

Gunn, J. (2005) 'The Readers of Hard Science Fiction' in Gunn, J. and Candelaria, M. (Eds.) Speculations on Speculation: Theories of Science Fiction, Lanham: Scarecrow Press, pp.8193.

Gwenllian-Jones, S. and Pearson, R.E. (Eds.) (2004) Cult Television. Minneapolis: University of Minnesota Press.

Hillegas, M.R. (1979) 'The Literary Background to Science Fiction' in Parrinder, P. (Ed.) Science Fiction: A Critical Guide. London: Longman.

Hills, M. (2007) 'From the Box in the Corner to the Box on the Shelf: "TVIII" and the Cultural/Textual Valorisations of DVD.' New Review of Film and Television Studies, 5 no. 1 (2007), pp.41-60.

Irwin, W. R. (1976) The Game of the Impossible: A Rhetoric of Fantasy. Urbana: University of Illinois.

Jackson, R. (1981) Fantasy: The Literature of Subversion. London: Methuen. James, E. (1994) Science Fiction in the Twentieth Century. Oxford: Oxford University Press. 
Volume 5, Issue 2

September 2012

Jancovich, M. and Lyons, J. (Eds.) (2003) Quality Popular Television. London: British Film Institute.

Johnson, C. (2005) Telefantasy. London: BFI.

Johnson-Smith, J. (2005) American Science Fiction TV: Star Trek, Stargate and Beyond. Middletown: Wesleyan University Press.

Joshi, S.T. (2004) The Evolution of the Weird Tale. New York: Hippocampus Press.

Ketterer, D. (1974) New Worlds for Old: The Apocalyptic Imagination, Science Fiction and American Literature. Garden City: Anchor Press.

Lavery, D. (2004) 'The X-Files' in Creeber, G. (Ed.) Fifty Key Television Programmes. London: Oxford University Press, 2004.

Lavery, D. (2008) ‘The Island's Greatest Mystery: Is Lost Science Fiction?' in Telotte, J.P. (Ed.) The Essential Science Fiction Television Reader. Lexington: University Press of Kentucky, pp.283-98.

Lovecraft, H.P. (2002) The Call of Cthulhu and Other Weird Stories, edited with Introduction and Notes by Joshi, S.T. London: Penguin.

Luckhurst, R. (2004) Science Fiction, Polity Press, Cambridge.

Malmgren, C.D. (1991) Worlds Apart: Narratology of Science Fiction. Bloomington; Indianapolis: Indiana University Press.

Neale, S. (2000) Genre and Hollywood. London: Routledge.

Nicholson, Marjorie Hope. (1960 [1948]) Voyages to the Moon. New York: MacMillan.

Parrinder, P. (Ed.) (1979) Science Fiction: A Critical Guide. New York: Longman.

Peeples, S. (1998) Edgar Allan Poe Revisited. New York: Twayne Press.

Pierce, J.J. (1987) Foundations of Science Fiction: A Study in Imagination and Evolution. New York: Greenwood Press.

Rickman, G. (2004) 'Introduction.' in Rickman, G. (Ed.) The Science Fiction Film Reader. New York: Limelight Editions, pp.xiii-xxxii.

Sassoon, D. (2006) The Culture of the Europeans: From 1800 to the Present. London: HarperPress.

Scholes, R. and Rabkin, E.S. (1977) Science Fiction: History, Science, Vision. New York: Oxford University Press.

Sconce, J. (2000) Haunted Media: Electronic Presence from Telegraphy to Television. Durham: Duke University Press. 
Volume 5, Issue 2

September 2012

Shelley, M. (1990 [1831]) 'Introduction to Frankenstein (1831)' in Bennett, B.T. and Robinson, C.E. (Eds.) The Mary Shelley Reader: containing Frankenstein, Mathilda, Tales and Stories, Essays and Reviews, and Letters. New York: Oxford University Press pp.167-71.

Short, S. (2011) Cult Telefantasy Series: A Critical Analysis of The Prisoner, Twin Peaks, The X-Files, Buffy the Vampire Slayer, Lost, Heroes, Doctor Who and Star Trek. Jefferson: McFarland.

Sobchack, V. (1987) Screening Space: The American Science Fiction Film. New York: Ungar.

Todorov, T. (1973) The Fantastic: A Structural Approach to a Literary Genre, trans. R. Howard. Cleveland: Western Reserve University.

Todorov, T. (1981) Introduction to Poetics, trans. R. Howard. Brighton: Harvester Press.

Turner, G. (1999) Film as Social Practice. London: Routledge.

Vest, J.P. (2007) 'The Truth is Back There: The X-Files and Early Science Fiction' in Yang, S.R. (Ed.) The X-Files and Literature: Unweaving the Story, Unraveling the Lie to Find the Truth. Cambridge: Cambridge Scholars Press pp.106-29.

Westfahl, G. (1998) The Mechanics of Wonder: The Creation of the Idea of Science Fiction. Liverpool: Liverpool University Press.

\section{Teleography}

Buffy the Vampire Slayer. (1997-2003) U.S.A.: Sandollar Television/Kuzui

Enterprises/Mutant Enemy/20th Century Fox Television.

- 'Once More With Feeling,' Buffy the Vampire Slayer. Episode 6.07. Dir. Joss Whedon. United Paramount Network. 2001, November 6.

CSI: Crime Scene Investigation. (2000- ) U.S.A./Canada: Jerry Bruckheimer Television/CBS Productions/Alliance Atlantis Communications/CBS Paramount Network Television.

Kolchak the Night Stalker. (1974-1975) U.S.A.: Universal TV/Francy Productions.

- ' 'They Have Been, They Are, They Will Be,' Kolchak the Night Stalker. Episode 1.03. Dir. Allen Baron. American Broadcasting Company. 1974, September 27.

- 'The Devil's Platform,' Kolchak the Night Stalker. Episode 1.07. Dir. Allen Baron. American Broadcasting Company. 1974, November 15.

- 'Mr. R.I.N.G,' Kolchak the Night Stalker. Episode 1.12. Dir. Gene Levitt. American Broadcasting Company. 1975, January 12.

- 'The Trevi Collection,' Kolchak the Night Stalker. Episode 1.14. Dir. Don Weis. American Broadcasting Company. 1975, January 24.

Law \& Order. (1990-2010) U.S.A.: Studios USA Television/Universal Network Television/NBC Universal Television.

Lost. (2004-2010) U.S.A.: Bad Robot/Touchstone Television/ABC Studios/Grass Skirt Productions. 
Volume 5, Issue 2

September 2012

NYPD Blue. (1993-2005) U.S.A.: Fox Television Network/20th Century Fox Television/Steven Bochco Productions.

The Twilight Zone. (1959-1964) U.S.A.: Cayuga Productions/Columbia Broadcasting System.

- 'The Monsters are Due on Maple Street,' The Twilight Zone. Episode 1.22. Dir. Ron Winston. Columbia Broadcasting System. 1960, March 4.

- 'It's a Good Life,' The Twilight Zone. Episode 3.08. Dir. James Sheldon. Columbia Broadcasting System. 1961, November 3.

Twin Peaks. (1990-1991) U.S.A.: Lynch\Frost Productions/Propaganda Films/Twin Peaks Productions/Spelling Entertainment.

The X-Files. (1993-2002) U.S.A./Canada: 20th Century Fox Television/Ten Thirteen Productions/X-F Productions.

- 'Ghost in the Machine,' The X-Files. Episode 1.06. Dir. Jerrold Freedman. Fox Network. 1993, October 29.

- 'The Host,' The X-Files. Episode 2.02. Dir. Daniel Sackheim. Fox Network. 1994, September 23.

- 'Colony,' The X-Files. Episode 2.16. Dir. Nick Marck. Fox Network. 1995, February 10.

- 'End Game,' The X-Files. Episode 2.17. Dir. Rob Bowman. Fox Network. 1995, February 17.

- 'The Post-Modern Prometheus,' The X-Files. Episode 5.05. Dir. Chris Carter. Fox Network. 1997, November 30.

- 'Bad Blood,' The X-Files. Episode 5.12. Dir. Cliff Bole. Fox Network. 1998, February 22.

- 'Patient X,' The X-Files. Episode 5.13. Dir. Kim Mannaers. Fox Network. 1998, March 1.

- 'Travelers,' The X-Files. Episode 5.15. Dir. William A. Graham. Fox Network. 1998, March 29.

- 'How the Ghosts Stole Christmas,' The X-Files. Episode 6.06. Dir. Chris Carter. Fox Network. 1998, December 13.

- 'Agua Mala,' The X-Files. Episode 6.13. Dir. Rob Bowman. Fox Network. 1999, February 21.

- 'Je Souhaite,' The X-Files. Episode 7.21. Dir. Vince Gilligan. Fox Network. 2000, May 14.

\section{Filmography}

Frankenstein. (1931) Dir. James Whale. U.S.A.: Universal Pictures. 